\title{
ESTUDO DA VIABILIDADE DA DOSAGEM DE RECICLADOS REFRATÁRIOS EM ARGAMASSAS SECAS E ÚMIDAS DE MESMA CLASSE*
}

Ana Luiza Chaves de Oliveira ${ }^{1}$ Manoel Robério Ferreira Fernandes ${ }^{2}$

\section{Resumo}

Com o avanço do conceito de sustentabilidade e as novas legislações ambientais, percebemos um crescente aumento da responsabilidade ambiental. As empresas cada vez mais investem em coletas seletivas, tratamento dos resíduos, etc., buscando minimizar os impactos ambientais, preservar os recursos naturais e assegurar a sustentabilidade. Tendo como objetivo apresentar uma solução integrada para a reciclagem e reaproveitamento dos resíduos refratários após o uso. Este trabalho propôs a produção de três classes de argamassas secas e úmidas através da utilização de reciclados. Foram realizadas quatro etapas (identificação visual das matérias-primas, cominuição, formulação/produção e acompanhamento durante a estocagem). Procurando avaliar 0 potencial dos reciclados 0 acompanhamento será realizado através da variação reológica e da determinação da força ligante após a fabricação e durante a estocagem (período de 12 meses). Os resultados evidenciaram que há potencial de reaproveitamento dos reciclados tanto na produção de argamassas secas e quanto úmidas sem que ocorra perda de suas propriedades reológicas, químicas e termo-mecânicas.

Palavras-chave: Argamassas; Reciclados; Sustentabilidade; Variação relógica.

\section{STUDY OF THE VIABILITY OF RECYCLED DOSAGE REFRACTORY IN MORTAR SAME CLASS DRY AND WET}

\section{Abstract}

Nowadays with the development of the sustainability conception and the new environment legislation, we note an increase of responsibility. The companies invest more in selective waste collection and treatment of it. Seeking for minimize the high environmental impacts, preserve the natural sources and ensure sustainability. The main aim is to present one integrate solution for recycling and reuse of refractory waste after use. This assignment proposed the production of three classes of dry and wet mortar using recycled. For stages were developed (visual identification of raw materials, comminution, formulation/production and monitored during the storage). Looking for evaluate the potential of recycled, the support is done by the variation of rheological and the determination of binder strength after the manufacture and during the storage (period of twelve months). Results have demonstrate that there is potential reutilization of refractory recycled in the production of dry and wet mortar without a significant loss of the properties.

Keywords: Mortar; Recycled; Sustainability; Variation of rheological.

1 Engenharia Metalúrgica, Bacharel, Estudante, Pontifícia Universidade Católica de Minas Gerais, Belo Horizonte, Minas Gerais, Brasil.

2 Engenharia de Minas, Doutor, Professor, IPUC Departamento de Engenharia Metalúrgica, Pontifícia Universidade Católica de Minas Gerais, Belo Horizonte, Minas Gerais, Brasil. 


\section{INTRODUÇÃO}

As indústrias de refratários apresentam um papel estratégico e importante nos processos industriais que utilizam altas temperaturas. No Brasil as indústrias de refratários estão bastante consolidadas, detendo $75 \%$ de todo mercado, tendo como principal consumidor a indústria siderúrgica, vindo a seguir fundições de ferro e aço, cimento e cal, não-ferrosos, vidros etc.

Os materiais refratários devem manter, armazenar e ceder calor, tendo como objetivo conter fluídos, resistir a solicitações mecânicas, térmicas e químicas, devendo suportar cargas sólidas e/ou liquidas.

O consumo desses materiais no Brasil em 1998 era próximo de 412 mil toneladas/ano tendo aumento de 559 mil toneladas/ano em 2013. Existem projeções que este consumo cresça $3,3 \%$ ao ano até 2028, apresentando como base a expectativa de crescimento da produção de aço e cimento, além do crescimento do PIB (Produto Interno Bruto) e redução do consumo específico.

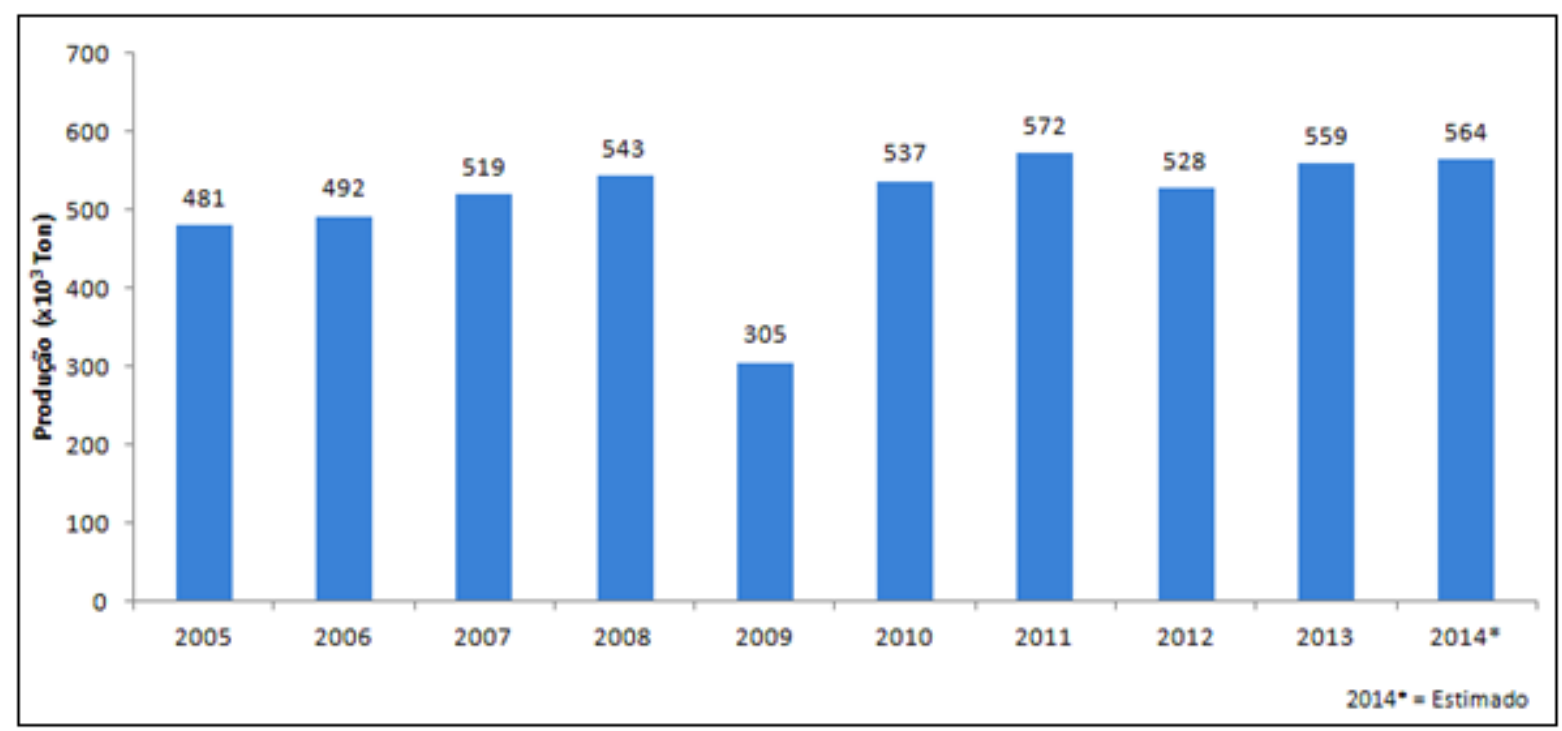

Figura 1. Evolução da produção de refratários no Brasil.

Com o crescimento acentuado das exportações no Brasil a produção de refratários saiu de 427 mil toneladas/ano em 1998 para 559 mil toneladas/ano em 2013. Devido à disponibilidade de insumos minerais projeta-se que a produção brasileira cresça $3,6 \%$ ao ano até 2028. (6) (8)

Com a crescente evolução do conceito de sustentabilidade, o descarte de resíduos torna-se não somente ambientalmente impactada, mas as questões econômicas também são afetadas. Tendo em vista que para cada tonelada de aço produzida cerca de $600 \mathrm{~kg}$ de resíduos (que compreendem os refratários) são gerados, o reuso ou a reciclagem destes resíduos nos próprios processos torna a atividade proveitosa.

Os resíduos refratários são denominados materiais post-mortem e apresentam ainda um potencial de uso em aplicações menos nobres do processo. Onde as solicitações químicas, mecânicas e térmicas não sejam tão elevadas quanto à aplicação inicial.

Devido as características estruturais, mecânicas e químicas necessárias para um boa performance de um refratário ao se utilizar resíduos, faz-se necessário avaliar os potenciais de aplicação destes resíduos através de suas propriedades. (5) (7) 
Este trabalho tem como objetivo avaliar o potencial de resíduos refratários na produção de argamassas secas e úmidas de mesma classe. Os resíduos escolhidos são provenientes de panelas de aço e gusa, forno de cimento, carro torpedo, carro distribuidor e mecanismo válvula gaveta.

\section{MATERIAIS E MÉTODOS}

Tendo como objetivo demonstrar as variações do comportamento reológico e das propriedades mecânicas para três diferentes classes de argamassas secas e úmidas produzidas com reciclados refratários e a base de bissilicato de sódio.

Após a produção, as argamassas são ensaiadas ao longo de 06 meses (to (produção), $t_{10}$ dias, $t_{30}$ dias, $t_{60}$ dias, etc). Os ensaios realizados para avaliar as propriedades físicomecânicas através da variação reológica e da determinação da força ligante, por meio dos períodos pré-determinados e determinando os parâmetros de: umidade, índice de penetração, força ligante e tempo de retenção de água. Além de um ensaio de análise química e refratariedade (CPE) visando determinar a refratariedade dos materiais produzidos com estes reciclados, indicando sua temperatura máxima de uso.

\subsection{Escolha dos Resíduos}

O trabalho teve inicio com a identificação visual dos reciclados refratários os quais foram agrupados por classe química, conforme figura 2.
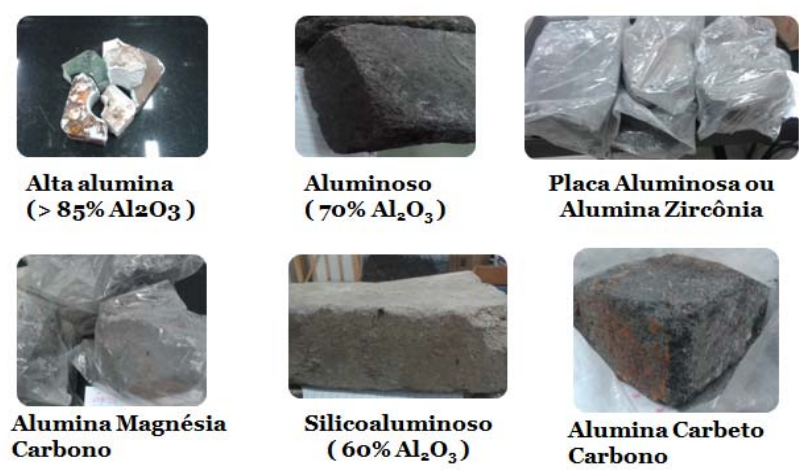

Figura 2. Resíduos refratários utilizados no estudo.

\subsection{Beneficiamento}

Como os resíduos foram recebidos sem nenhum tipo de beneficiamento, fez-se necessário realizar o processo de beneficiamento de cada reciclado, visando transformá-lo em matéria reciclada com potencial de utilização.

Foram realizados os processos de desintegração manual britagem, moagem, separação magnética e peneiramento. Tendo como objetivo obter frações menores que $600 \mu \mathrm{m}$. Para aplicação das argamassas é utilizado juntas entre 1 a $3 \mathrm{~mm}$, portanto não é possível desta forma utilizar matérias-primas com grãos acima de $1,00 \mathrm{~mm}$.

\subsection{Formulação}

As formulações foram desenvolvidas através do conhecimento prévio e experiência profissional do orientador deste trabalho. Conforme tabela 1, a quantidade de $70 \%$ 
de reciclado na formulação foi utilizada com o intuito de colocar a quantidade máxima de reciclado que se pode utilizar em função dos outros componentes. Através dos resultados apresentados com $70 \%$ de reciclado podemos supor que em menor quantidade o resultado seria ainda melhor e sugerir novos estudos visando adequar a quantidade de reciclados à necessidade de características reológicas e termomecânicas de cada classe, dentro do período de vida útil previsto para as mesmas.

Tabela 1. Formulação.

\begin{tabular}{l|c|c|c|c|c|c}
\hline \multicolumn{1}{c|}{ Matérias Primas } & $\mathbf{A ~ ( \% )}$ & $\mathbf{B ( \% )}$ & $\mathbf{C ( \% )}$ & $\mathbf{D ( \% )}$ & $\mathbf{E}(\%)$ & $\mathbf{F}(\%)$ \\
\left.\hline Tijolo Silicoaluminoso( $45{\left.\mathrm{a} 60 \% \mathrm{Al}_{2} \mathrm{O}_{3}\right)}\right)$ & 70 & 0 & 0 & 0 & 0 & 0 \\
\hline Tijolo Aluminoso ( $\left.70 \mathrm{a} 85 \% \mathrm{Al}_{2} \mathrm{O}_{3}\right)$ & 0 & 70 & 0 & 0 & 0 & 0 \\
\hline Tijolo Alta alumina $\left(>85 \% \mathrm{Al}_{2} \mathrm{O}_{3}\right)$ & 0 & 0 & 70 & 0 & 0 & 0 \\
\hline Tijolo Alumina Carbeto Carbono (ACC) & 0 & 0 & 0 & 70 & 0 & 0 \\
\hline Tijolo Alumina Magnésia Carbono (AMC) & 0 & 0 & 0 & 0 & 70 & 0 \\
\hline Placa Aluminosa ou Alumina Zircônia & 0 & 0 & 0 & 0 & 0 & 70 \\
\hline Argila Rosa & 15 & 15 & 15 & 15 & 15 & 15 \\
\hline Bissilicato de sódio em Pó & 09 & 09 & 09 & 09 & 09 & 09 \\
\hline Carboximetilcelulose (CMC) & 0,1 & 0,1 & 0,1 & 0,1 & 0,1 & 0,1 \\
\hline
\end{tabular}

* Quantidade adicionada por fora (PF): como objetivo conferir trabalhabilidade, plasticidade e aumentar o tempo de retenção de água.

\subsection{Produção e Estocagem}

Foram produzidas $5 \mathrm{~kg}$ de cada argamassa úmida conforme formulação descrita no item 2.3. A quantidade de água, conforme tabela 2, foi definida através do conhecimento prévio em função da penetração $(380-400 \mathrm{~mm})$. As argamassas prontas foram armazenadas em potes individuais, devidamente identificados e guardadas em ambiente seco e livre das ações do tempo.

Tabela 2. Quantidade de água (I) em cada argamassa produzida.

\begin{tabular}{c|c}
\hline ARGAMASSA & Água (l) \\
\hline Alumina Carbeto Carbono & 2,225 \\
\hline Magnésia Alumina Carbono & 1,875 \\
\hline Alta alumina $\left(>85 \% \mathrm{Al}_{2} \mathrm{O}_{3}\right)$ & 1,500 \\
\hline Alumina Zircônia & 1,750 \\
\hline Silicoaluminoso $\left(60 \% \mathrm{Al}_{2} \mathrm{O}_{3}\right)$ & 1,750 \\
\hline Aluminoso $\left(70 \% \mathrm{Al}_{2} \mathrm{O}_{3}\right)$ & 1,750 \\
\hline
\end{tabular}

\subsection{Ensaios}

Durante os tempos estabelecidos, apresentados no item 2, mediante o conhecimento prévio sobre a perda da consistência no início da estocagem. Foram estudadas e avaliadas as seguintes características das argamassas ao longo da estocagem, através dos seguintes ensaios específicos: Umidade, Consistência (Penetração), Tempo de retenção de água, Força ligante 110 e $1400{ }^{\circ} \mathrm{C}$, Análise química por FRX (Fluorescência de Raio X) e Cone Pedométrico Equivalente (CPE). (2) (3) (4) 


\subsubsection{Umidade}

Determina a perda de água após secagem (estufa a $110^{\circ} \mathrm{C}$ por 24 horas). Tem como objetivo verificar a eficácia do sistema de embalagem durante a estocagem. A norma ABNT NBR 6945 determina o teor de umidade de matérias-primas e refratários não moldados. (2) (3) (4)

\subsubsection{Consistência (Penetração)}

O ensaio de consistência também conhecido como penetração, tem como objetivo realizar a medida do índice de penetração da argamassa durante o processo produtivo ou na estocagem. O resultado expressa indiretamente a viscodidade da argamassa e durante o processo produto com o ensaio de consistência é possível ajustar a trabalhabilidade da argamassa produzida. $O$ equipamento típico para este ensaio é o penetrômetro universal e a norma utilizada é a ABNT NBR 11508. (2) (3) (4)

\subsubsection{Tempo de Retenção de água}

Este ensaio tem como objetivo determinar o tempo que a argamassa levará para unir dois tijolos. Para realizar o presente ensaio é necessário dois tijolos de mesma classe da argamassa. Coloca-se então uma camada de argamassa $( \pm 3 \mathrm{~mm})$ na superfície de um dos tijolos. O tempo de retenção de água é então determinado através de movimentos longitudinais do tijolo superior sobre o inferior, até que o movimento não seja possível e ao levantar o tijolo superior o inferior seja suspenso também. (2) (3) (4)

\subsubsection{Força Ligante}

O ensaio de força ligante mede tensão de ruptura sob uma taxa de deformação constante, através de um teste de flexão convencional de três pontos. O presente ensaio também é conhecido como módulo de ruptura da junta, tem como objetivo determinar a força de ligação da argamassa após a secagem ou o tratamento térmico. (2) (3) (4)

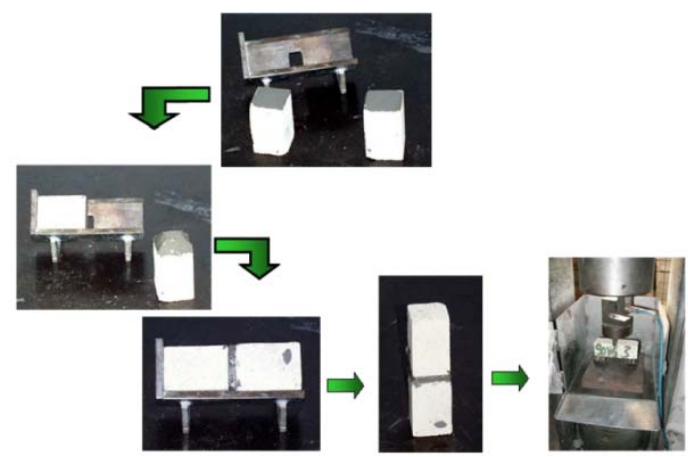

Figura 3. Sequência do ensaio de força ligante.

\subsubsection{Análise Química por FRX}

O resultado da análise química serve como suporte para a classificação do refratário e um guia para as suas propriedades químicas e refratariedade. Pode ser utilizado também como controle de qualidade das matérias-primas utilizadas.

O processo de Fluorescência de raios-X (FRX), consiste na excitação da amostra através da irradiação de um feixe primário de raios-X. A análise quantitativa consiste na medida das linhas do espectro característico dos elementos procurados e do relacionamento de valores de intensidade. (2) (3) (4) 


\subsubsection{Cone Pirométrico Equivalente (CPE)}

Avalia o comportamento do refratário quanto ao amolecimento em altas temperaturas. Uma amostra do material é moldado na forma de um cone e montado em placas cerâmicas com diversos cones padrões de refratariedade conhecida. A placa cerâmica é colocada em um forno rotativo onde a temperatura aumenta gradativamente. O resultado é obtido quando um cone padrão virar na mesma temperatura que o da amostra testada.

Este ensaio não indica o ponto de fusão correto, pois é uma comparação do comportamento térmico da amostra em relação aos cones padrões. É utilizado para avaliar a refratariedade do material que esta sendo testado. (2) (3) (4)

\section{RESULTADOS E DISCUSSÃO}

\subsection{Análise Química (ABNT - NBR 6946)}

Tabela 3. Resultados Análise Químicas dos produtos por FRX.

\begin{tabular}{|c|c|c|c|c|c|c|}
\hline & $\begin{array}{c}\text { Alumina } \\
80 / 90\end{array}$ & $\begin{array}{c}\text { Silico } \\
\text { Aluminoso } \\
\end{array}$ & $\begin{array}{c}\text { Aluminoso } \\
70\end{array}$ & $\mathrm{AMC}^{1}$ & $A C C^{2}$ & $\begin{array}{l}\text { Alumina } \\
\text { Zircônia }\end{array}$ \\
\hline $\mathrm{PF}^{3}(\%)$ & 4,56 & 3,88 & 3.33 & - & - & - \\
\hline $\mathrm{SiO}_{2}(\%)$ & 16,68 & 40,42 & 33.2 & 28.64 & 16.12 & 22.3 \\
\hline $\mathrm{TiO}_{2}(\%)$ & 0,39 & 2,47 & 3.18 & 0.96 & 0.96 & 0.359 \\
\hline $\mathrm{Al}_{2} \mathrm{O}_{3}(\%)$ & 73,26 & 50,84 & 56.61 & 56.03 & 65.42 & 70.8 \\
\hline $\mathrm{Cr}_{2} \mathrm{O}_{3}(\%)$ & 0,13 & 0,06 & 0.04 & 0.06 & 0.038 & 0.02 \\
\hline $\mathrm{Fe}_{2} \mathrm{O}_{3}(\%)$ & 1,87 & 1,98 & 2.79 & 2.43 & 1.58 & 0.809 \\
\hline MnO (\%) & 0,13 & 0,05 & 0.12 & 0.16 & 0.076 & - \\
\hline $\mathrm{CaO}(\%)$ & 1,23 & 0,27 & 0.15 & 0.52 & 0.153 & 0.08 \\
\hline MgO (\%) & 2,28 & 0,31 & 0.15 & 7.33 & 11.69 & 0.12 \\
\hline $\mathrm{Na}_{2} \mathrm{O}(\%)$ & 3,39 & 2,92 & 34.1 & 3.18 & 3.24 & 3.039 \\
\hline $\mathrm{K}_{2} \mathrm{O}(\%)$ & 0,17 & 0,4 & 0.23 & 0.26 & 0.16 & 0.2 \\
\hline $\mathrm{P}_{2} \mathrm{O}_{5}(\%)$ & 0,44 & 0,19 & 0.03 & 0 & 0.048 & - \\
\hline $\mathrm{ZrO}_{2}$ & 0,01 & 0,08 & 0.09 & 0.43 & 0.34 & 2.259 \\
\hline $\mathrm{Na}_{2} \mathrm{O}+\mathrm{K}_{2} \mathrm{O}(\%)$ & - & - & 3.64 & - & - & - \\
\hline Carbono Total (\%) & - & - & - & 11.07 & - & 5.53 \\
\hline Carbono Livre (\%) & - & - & - & - & 7.11 & - \\
\hline $\operatorname{SiC}(\%)$ & - & - & - & - & 0.13 & - \\
\hline
\end{tabular}

${ }^{1}$ Alumina Magnésia Carbono; ${ }^{2}$ Alumina Carbeto Carbono; ${ }^{3}$ Quantidade Por Fora;

Como podemos observar na tabela 3 os resultados confirmaram as classificações prévias das MPs (Matérias-Primas). Observa-se um elevado nível de Alkali ( $\mathrm{Na}_{2} \mathrm{O}+$ $\mathrm{K}_{2} \mathrm{O}$ ) evidenciando a presença do sistema ligante a base de bissilicato de sódio nas argamassas. A presença de óxidos em níveis mais elevados, como $\mathrm{MgO}$, os quais não são comuns e poderiam afetar drasticamente a reologia do sistema se estivesse 
na forma livre. Entretanto, presume-se que este se encontre em sua forma combinada já espinelizada, a qual é estável, pois a reologia do sistema não foi afetada durante a estocagem.

\subsection{Penetração (ABNT - NBR11508)}

Tem como objetivo determinar a consistência da argamassa com o auxílio do aparelho penetrômetro universal. O processo de medição necessita de constante limpeza e lubrificação do equipamento antes da realização da medida da consistência, para se evitar interferências durante o processo de medição.

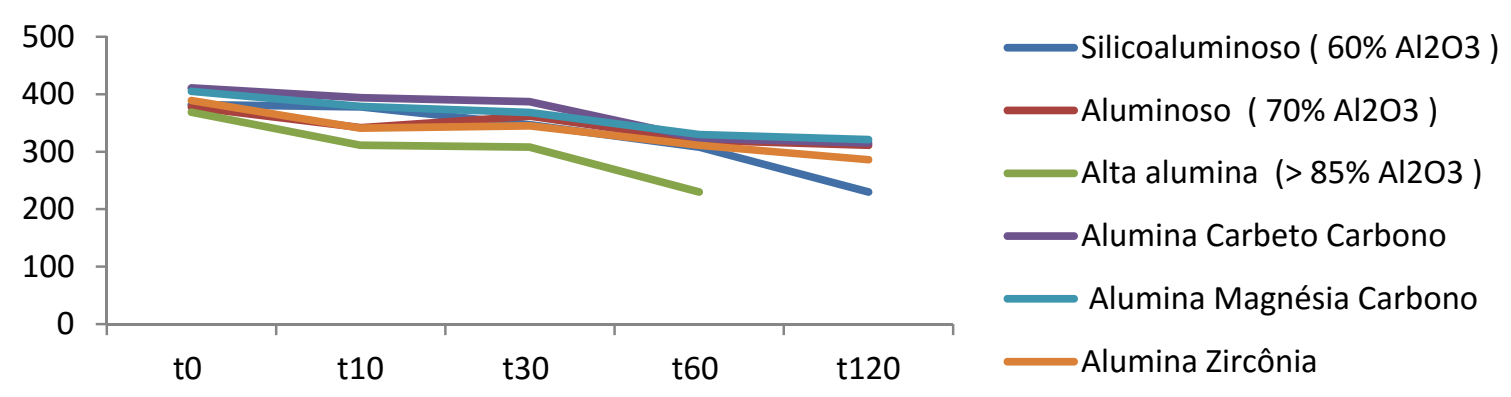

Figura 4. Penetração ao longo do período de estocagem.

\subsection{Umidade (ABNT - NBR 6945)}

Como podemos observar na figura 4, percebemos que assim como o esperado, não ocorreram significativas perdas de água ao longo da estocagem, com exceção da argamassa base alumina carbeto carbono para a qual se atribui a perda de água à reações secundárias evidenciadas pela liberação de odor forte e característico de amônia.

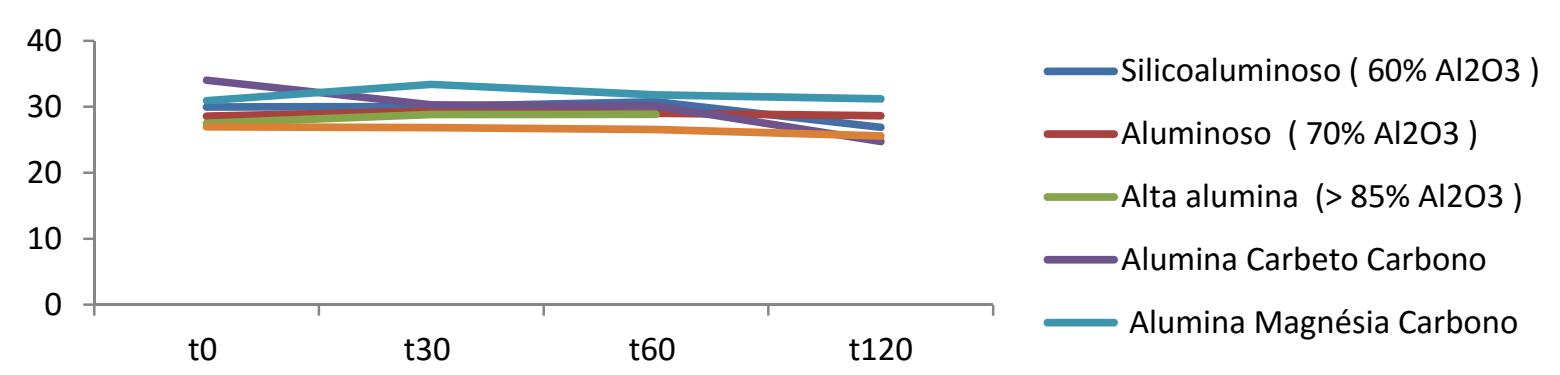

Figura 5. Umidade ao longo do período de estocagem.

\subsection{Tempo de Retenção (ABNT - NBR 8827)}

Este ensaio tem como objetivo determinar o tempo que a argamassa levará para unir dois tijolos, sendo que após este tempo não seja mais possível deslizar, ajustar e unir um tijolo sobre o outro. O tempo de retenção de água é determinado quando o tijolo inferior é arrastado pela força exercida no tijolo superior, por meio de movimentos longitudinais, conforme figura 5.

Para realizar este ensaio devem-se ter os tijolos da mesma classe química da argamassa que será ensaiada. Conforme tabela 4, podemos somente realizar o teste em duas argamassas, pois os tijolos obtidos pertenciam a mesma classe química das argamassas: Aluminoso $\left(70 \% \mathrm{Al}_{2} \mathrm{O}_{3}\right)$ e Silicoaluminoso $\left(60 \% \mathrm{Al}_{2} \mathrm{O}_{3}\right)$. 
Tabela 4. Resultados Tempo de Retenção.

\begin{tabular}{c|c|c}
\hline Argamassa & Tempo (s) (A) & Tempo (s) (B) \\
\hline Aluminoso $\left(70 \% \mathrm{Al}_{2} \mathrm{O}_{3}\right)$ & 57 & 47 \\
\hline Silicoaluminoso $\left(60 \% \mathrm{Al}_{2} \mathrm{O}_{3}\right)$ & 34 & 36 \\
\hline \multicolumn{2}{|c}{} \\
\hline
\end{tabular}

Figura 6. 1Tempo de Retenção.

Observa-se na tabela 4 que as características reológicas determinadas logo após produção $(A)$ e após 120 dias (B), por este método de determinação do tempo de retenção de água, também não se alteraram de maneira significativa ao longo do período de sua estocagem, mantendo-se em todos os casos acima de 30 segundos, limite mínimo de trabalhabilidade especificado no meio refratarista para assentamento de tijolos.

\subsection{Força Ligante (ABNT - NBR 8384)}

Tabela 5. Resultados Força Ligante.

\begin{tabular}{c|c|c|c|c}
\hline \multirow{2}{*}{ ARGAMASSA } & \multicolumn{2}{|c|}{ FL $\mathbf{1 1 0} \mathbf{}^{\circ} \mathbf{C}(\mathbf{M P a})$} & \multicolumn{2}{c}{ FL $\left.\mathbf{1 4 0 0} \mathbf{0}^{\circ} \mathbf{C} \mathbf{M P a}\right)$} \\
\cline { 2 - 5 } & Média & DP & Média & DP \\
\hline Silico aluminoso & 2,2 & 0,9 & 4,8 & 1,5 \\
\hline Aluminoso 70 & 4,5 & 1,1 & 4,5 & 2,1 \\
\hline Alumina 80/90 & 1,7 & 1,2 & 13,5 & 12,9 \\
\hline Alumina Zircônia & 3,2 & 0,6 & 20,3 & 9,0 \\
\hline Alumina Carbeto Carbono & 1,0 & 0,8 & 9,7 & 4,0 \\
\hline Alumina Magnésia Carbono & 0,6 & 0,3 & 6,8 & 1,9 \\
\hline
\end{tabular}

Analisando a tabela 5 , verificamos que mesmo com um desvio padrão considerável e erros oriundos do processo de amostragem, posicionamento das amostras sob o cutelo da máquina de compressão e medição, estes desvios são considerados normais no meio refratarista.

Os resultados após queima de algumas argamassas apresentarem tão elevados são devido a forte ceramização, advindas da formação de fases liquidas durante o tratamento térmico. O desejável é que não ultrapassem $10 \mathrm{MPa}$, pois acima deste valor vão se tornando cada vez mais rígidas perdendo uma de suas finalidades, a de alivio de tensão dos revestimentos.

Durante o teste de força ligante à $1400{ }^{\circ} \mathrm{C}$ observamos o aumento da resistência para as argamassas de Alumina Zircônia, Alumina Magnésia Carbono e Alumina Caberto Carbono. Portanto realizamos uma caracterização da interface argamassa/tijolo através do método DRX (Difração de Raio X), conforme resultados apresentado na tabela 6 .

Tabela 6. Resultados DRX.

\begin{tabular}{c|c}
\hline ARGAMASSA & FASES \\
\hline Alumina Zircônia & Corindon \\
\hline Alumina Carbeto Carbono & Coridon, Mulita e Espinélio \\
\hline Alumina Magnésia Carbono & Corindon, Mulita e Tielita \\
\hline
\end{tabular}


As fases encontradas na Alumina Zircônia e Alumina Carbeto Carbono estão dentro do esperado. Porém a Tielita encontrada na Alumina Magnésia Carbono, acreditamos que tenha sido formada através do contato entre o aço e o refratário (por meio de uma infiltração), pois para essa argamassa o reciclado é proveniente da panela de aço. Portanto, provavelmente continha Titânio (Ti) na liga de aço e quando ocorreu o processo de beneficiamento não foi retirar todas as impurezas.

A combinação dos óxidos $\mathrm{TiO}_{2}-\mathrm{Fe}_{2} \mathrm{O}_{3}-\mathrm{SiO}_{2}$ formam um composto de baixo ponto de fusão $\left(<1.300^{\circ} \mathrm{C}\right)$. Consequentemente a Tielita por possuir baixo ponto de fusão, formou fase liquida no aquecimento a $1400^{\circ} \mathrm{C}$ para realizar o teste de força ligante e após a solidificação ocorreu à interferência nos resultados.

\subsection{Cone Pirométrico Equivalente (CPE) (ABNT - NBR ISO 528)}

Teste realizado após 120 dias para determinar a refratariedade simples (ponto de amoleciamento), por meio da determinação dos efeitos tempo-temperatura, nos processos de aquecimento dos cones, figura 6 , com os cones padrões de temperatura conhecida.

Este ensaio para refratários é muito importante, pois informa a temperatura máxima em que os refratários poderão ser submetidos sem comprometimentos de suas características termomecânicas.

Observando os resultados na tabela 7 , somente a argamassa contendo ACC (Alumina Magnésia Carbono) não está adequada para uso nesta proporção de reciclados.

Tabela 7. Resultados CPE.

\begin{tabular}{c|c}
\hline ARGAMASSA & Temp. ( $\left.{ }^{\circ} \mathbf{C}\right)$ \\
\hline Alumina Carbeto Carbono & 1190 \\
\hline Aluminoso ( 70\% Al2O3 ) & 1435 \\
\hline Alumina Zircônia & 1491 \\
\hline Silicoaluminoso ( 60\% Al2O3 ) & 1532 \\
\hline Alumina Magnésia Carbono & 1710 \\
\hline
\end{tabular}

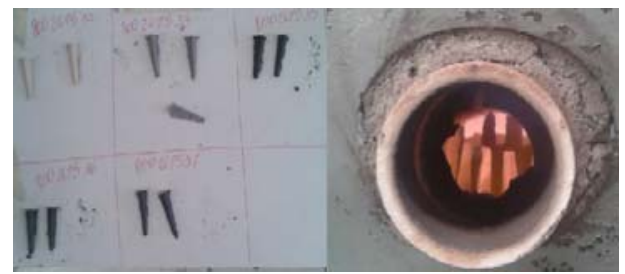

Figura 7. Teste CPE.

\subsection{Características Gerais}

Durante o processo de produção e estocagem podemos perceber algumas características peculiares que não observamos em argamassas que não possuem reciclados em sua composição. Destacamos dentre elas:

- Exsudação: fenômeno migratório da água existente na composição para a superfície. Este acontecimento pode comprometer a durabilidade do produto, como pode ser observado na figura 7. 


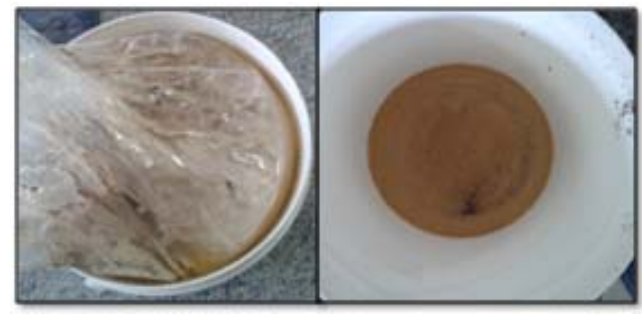

Figura 8. Exsudação

- Cores características: Podemos destacar que as argamassas tiveram suas cores definidas de acordo com a cor do reciclado, como pode ser observado na figura 8.

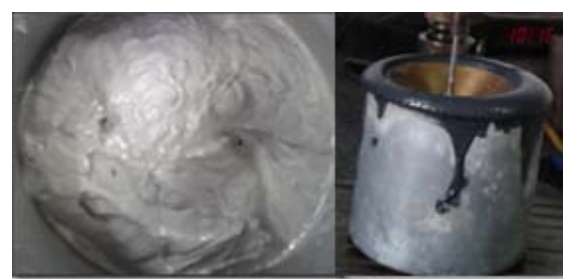

Figura 9. Cores das argamassas.

- Expansão durante o aquecimento à $110^{\circ} \mathrm{C}$ : para realizar a análise química fez-se necessário aquecer as argamassas com o intuito de retirar os voláteis e a umidade da massa. Durante este processo, podemos observar uma expansão do material (figura 9).

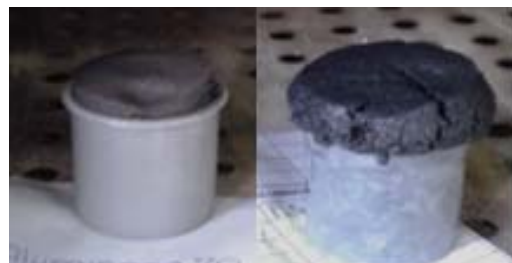

Figura 10. Expansão durante o processo de aquecimento a $110^{\circ} \mathrm{C}$

- Odor de amônia: a argamassa produzida com Alumina Magnésia Carbono (AMC) apresenta um cheiro de amônia característico e irritante, devido à reações secundárias de oxidação de metálicos em meio fortemente alcalino.

- Endurecimento da Alumina 80/90: Após 120 dias observamos o endurecimento da argamassa de alta alumina, não sendo possível a mensuração da consistência pelo método do penetrômetro. Portanto para estas argamassas suspendemos os testes de determinação da consistência após 60 dias, o último realizado. Este fato pode estar relacionado á elevada porosidade do reciclado de alta alumina utilizado nesta classe, os quais absorveram a água livre do sistema mesmo com a alteração de sua vicosidade pelo CMC. A água livre é uma das responsáveis por manter a trabalhabilidade do sistema.

\section{CONCLUSÃO}

Mediante aos resultados apresentados podemos concluir que os resíduos refratários mostraram-se processáveis e aplicáveis com a escolha de uma granulometria adequada e não prejudicam as propriedades termomecânicas das argamassas. A metodologia mostrou-se apropriada para avaliação reológica e físico-mecânica das argamassas produzidas. 
Nas proporções de $70 \%$ de reciclado na composição, consideramos os resultados satisfatórios, mesmo sem a conclusão total dos 12 meses de teste. Provamos assim que estes materiais apresentam potencial de reciclagem e reuso, para trabalhos futuros visando refinamentos das formulações para maximizar a performance de cada classe de argamassas refratárias torna-se necessário realizar uma avaliação das propriedades finais requeridas por cada aplicação para criar formulações específicas visando atender as solicitações dos equipamentos.

Apesar de não termos estudado a introdução de reciclados em argamassas secas, admitimos que para estas, o potencial de uso de reciclados até estes níveis estudados seja possível, pois a diferença entre elas é somente a adição de água e o preparo da mistura, o qual é realizado in loco. Neste caso, portanto não corre o risco de perder as propriedades, aqui estudadas, durante a aplicação e utilização com processo de estocagem.

\section{Agradecimentos}

Agradecemos aos colegas da Magnesita Refratário S.A., ACICIA Indústria e Comercio, Ferro Ligas Brasil Ltda. e PUC Minas pela ajuda e apoio. À PUC Minas pela bolsa concedida (projeto FIP $1^{\circ}$ 2015/9472-S1).

\section{REFERÊNCIAS}

1 CARNIGLIA, S. C.; BARNA, G. L.; Handbook of Industrial Refractories Technology Principles, Types, Properties and Applications. Ed. Noyes; 1992.

2 FERNANDES, M. Robério F.; BRANDÃO, Paulo R. G.; SILVA, S. L. C.; Effect Of Storage Time In The Workability Of Wet Refractory Mortars. In: CONGRESSO ALAFAR, 2014.

3 FERNANDES, Manoel Robério Ferreira. 2012. $231 \mathrm{f}$. Tese (Doutorado) - Universidade Federal de Minas Gerais, Estudo das propriedades das argamassas refratárias úmidas com o tempo de estocagem. Belo Horizonte: UFMG, 2012.

4 FERNANDES, Manoel Robério Fernandes. Notas de aula da disciplina "Materiais Refratários" - Curso de Engenharia Metalúrgica da Pontifícia Universidade Católica de Minas Gerais. Belo Horizonte, 2014.

5 FONSECA, Daniele. Desenvolvendo Sustentabilidade na Indústria de Refratários. Magnesita Refratários S/A. Disponível em: < http://www.fdc.org.br/professoresepesquisa/nucleos/Documents/apresentacao_daniele fonseca_magnesita.pdf>. Acesso em: 16 jun. 2015.

6 LOBATO, Emilio. Relatório Técnico 71 - Refratários - Cadeia de refratários. Projeto de Assistência Técnica ao setor de energia. J-Mendo Consultoria. Agosto, 2009.

7 SILVA, R. Diego S. Avaliação do Potencial de Reutilização de Resíduos Refratários em Massas Refratárias. 2011. $31 \mathrm{f}$. Trabalho de Diplomação - Universidade Federal do Rio Grande do Sul, Escola de Engenharia, Engenharia de Materiais, Porto Alegre, 2011.

8 ASOCIACION LATINOAMERICANA DE FABRICANTES DE REFRACTARIOS. ESTADISTICAS CUADROS RESUMEN, Datos Estadisticos Industria de Refractarios. ALAFAR, 2014. Disponível em: <http://www.alafar.org/>. Acesso em: 08 mar. 2016. 